\title{
Toxic shock syndrome, tampons and laboratory standard-setting
}

Cite as: CMAJ 2017 May 23;189:E726-8. doi: 10.1503/cmaj.161479

CMAJ Podcasts: author interview at https://soundcloud.com/cmajpodcasts/161479-medsoc

n 1980, the Centers for Disease Control and Prevention (CDC) in the United States implicated Rely tampons, produced by Procter \& Gamble, as the single tampon most contributing to the onset of toxic shock syndrome. Pressured by the US Food and Drug Administration (FDA) and threatened with a recall, the company withdrew unpurchased boxes from store shelves. The urgency was reinforced through television, radio and newspaper advertisements that instructed women to stop using Rely and seek refunds. ${ }^{1}$ The CDC urged all women to minimize use and avoid, if possible, superabsorbent tampons because this category had the greatest association with toxic shock syndrome. However, without accurate and standardized labelling about absorption, women could not easily follow this recommendation.

The FDA requested a voluntary tampon standard among stakeholders, and the Tampon Task Force resulted. However, the process to agree upon a standard had difficulties on multiple fronts: the administration of President Ronald Reagan was not supportive of new federal regulations; industries resisted changes to tampon packaging and product design because profitability could be threatened; feminist activists questioned the validity of corporate data and sought their own; and arguments ensued concerning the efficacy of the syngyna synthetic vagina laboratory apparatus to set standards for tampon absorbency. Although the task force disbanded without agreement in 1985 , the process of bringing consumers, activists and corporate representatives together marked an important precedent in standard setting.
Although the exact mechanism of how tampons precipitated toxic shock syndrome was not entirely clear at the time, epidemiologists determined that superabsorbent tampons were a co-factor, thus tamponrelated toxic shock syndrome became a legitimate illness. ${ }^{2}$ Between 1970 and 1980, there were 941 confirmed cases of toxic shock syndrome, 928 in women, and 905 at the onset of menstruation, in which 73 women died. ${ }^{3}$ Hundreds more were sickened but did not meet the strict case definition of toxic shock syndrome. ${ }^{4}$ Because women had been acculturated to use tampons to manage menstrual flow and, moreover, viewed them as a physically liberating technology, many were enraged that tampons amounted to a ticking time bomb.

To be clear, tampons do not cause toxic shock syndrome and, although corporate lawyers refer to this assertion, tampons are indeed a co-factor in many cases.
Men, children and nonmenstruating women can still contract toxic shock syndrome, but tampons are the catalyst for many menstruating women. Toxic shock syndrome specific to tampons requires the presence of Staphlococcus aureus in vaginal flora and lack of requisite antibodies to neutralize toxic shock syndrome toxin-1 (TSST-1) produced by the bacteria. Many scientists believe that other co-factors include: oxygen (brought into the vaginal canal by the tampon) that creates an aerobic rather than anaerobic environment, a less acidic environment during menses, and dynamic vaginal ecosystems that influence microbial constituency and activity including that of S. aureus. ${ }^{5}$ However, most of this was not known at the time of the withdrawal of Rely. What was clear was the link between superabsorbent tampons and toxic shock syndrome, and the $C D C$ recommendation to use the

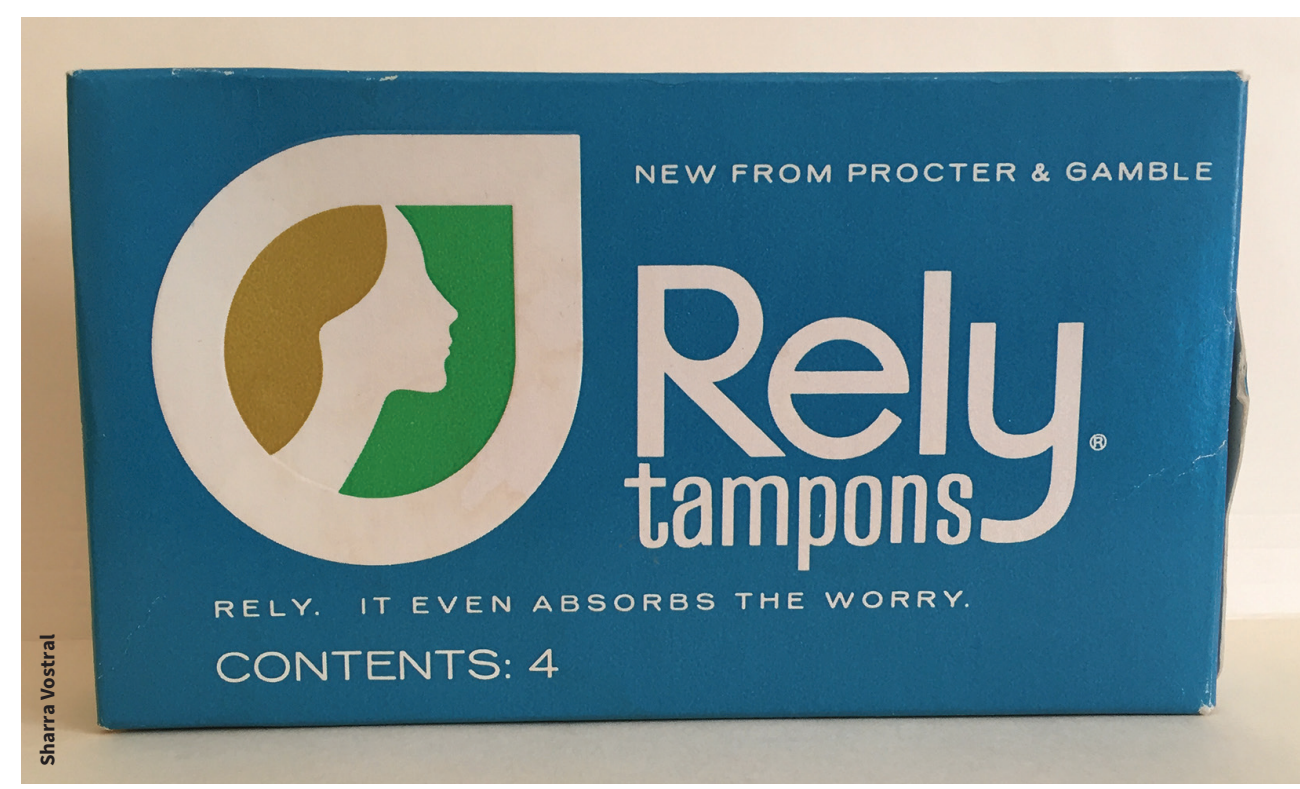


least absorbent tampon was difficult to follow when tampon boxes were not labelled to indicate actual absorbent capacity.

At the request of the FDA, The Tampon Task Force was convened in 1982 by the American Society for Testing and Materials (ASTM), a neutral organization that was established to promote the setting of standards across industries. Because tampons fell under Class II of the Medical Device Amendments of 1976, the FDA needed guidelines to be established by important stakeholders in order to propose federal policy. Task force participants included manufacturers such as Kimberly-Clark, Playtex International and Tambrands, who were motivated to both defend their products and also engender trust that tampons were safe. Also represented were consumer groups who held a more critical position (i.e., Empire State Consumer Association, National Consumers League, National Women's Health Network, Woman Health International and the Boston Women's Health Book Collective).

Esther Rome from the Boston Women's Health Book Collective, who cowrote the influential Our Bodies, Ourselves (1973), insisted that women needed accurate scientific information about the interrelationship of tampons and menstruation, and this characterized her approach to policy setting.

After months of meetings, the Tampon Task Force focused solely on absorptive capacity in terms of a measurable gram weight of fluid held by any given tampon, the creation of absorbency ranges and standardized nomenclature to define each range. This caused concern for manufacturers by creating mismatched absorbency ratings to the language that was used in product advertising; some would have to either change the absorptive capacity of their tampons to fit a category (either moving it up or down the scale to match the nomenclature) or advertise the product with the accurate terminology. For example, a tampon may formerly have been a "super," but was actually a "regular" under the proposed policy. Manufacturers were concerned about losing revenue from consumers who were disenchanted by a change to a familiar product.

At stake was the industry-wide practice of measuring tampon absorbency with the laboratory apparatus known as the syngyna (or syngina), the synthetic vagina. ${ }^{6}$ This equipment simulated body temperature, vaginal pressure and flow rates of a saline solution to mimick a menstrual period, while eliminating variables except that of the tampon. Therefore, part of the process of standardizing ranges for tampon absorbency required agreement about the efficacy of the process and laboratory method itself. Manufacturers had the advantage of in-house scientists to produce their own studies of absorbency, which consumer groups and feminist activists understood were not value-free.

From her past work on Our Bodies, Ourselves, Rome knew that consumer groups and feminist activists needed to seek and gain their own scientific knowledge because of testing flaws. An obvious oversight perpetuated the exclusion of women's bodily experiences with menstruation and menstrual blood in the syngyna methodology. Menstrual flow rates are anything but consistent, changing from the start to the end of a period, with actual menstrual fluid ranging from thin and watery to globular blood clots. What would it mean for the standard to be based upon a saline solution rather than real-life conditions of blood, mucus and the biological debris of menses? This was not being investigated by the corporate researchers. Expedience trumped these concerns, with ignorance at best and sexism at worst influencing scientific practice.

Rome enlisted Nancy Reame, a newly hired professor of nursing at the University of Michigan to run their needed laboratory work. She followed the syngyna protocol with saline but also tested the method with heparinized blood. ${ }^{7}$ The manufacturers, she recalled, did not like using blood because it coagulated, but the heparinized blood acted more like menstrual blood than saline. What Reame found was that the relative rank of tampons remained the same, but the more highly absorbent tampons absorbed more blood than saline. ${ }^{8}$ In terms of setting a standard, this meant that some tampons would be miscategorized and mislabelled. A lower-ranked tampon with the saline test would likely rise to the upper end of absorbency with the blood test. Setting a standard based upon the test method could provide misleading information to women for making their tampon choices.

Rome and Reame were unsuccessful in swaying members of the Tampon Task Force to alter the testing method, and it disbanded in 1985, with the saline-based syngyna testing method still in use by manufacturers. ${ }^{9}$

Owing to delays and a lack of progress, the Boston Women's Health Book Collective mobilized a letter-writing campaign to the FDA, and the Public Citizen Health Research Group sued the FDA in 1988 and helped to set in motion federal guidelines for tampon labelling. In 1990, the FDA drew upon many of the findings of the Tampon Task Force and required boxes to display a specific set of ranges and accompanying language: $6 \mathrm{~g}$ or less (junior absorbency), greater than $6 \mathrm{~g}$ up to and including $9 \mathrm{~g}$ (regular absorbency), greater than $9 \mathrm{~g}$ up to and including $12 \mathrm{~g}$ (super absorbency) or greater than $12 \mathrm{~g}$ up to and including $15 \mathrm{~g}$ (super plus absorbency). ${ }^{10}$

Analyzing the intersection of menstruation, tampons, laboratory practices and policy-making during the 1980s highlights the important health outcomes related to standard setting. The intuitive understanding of Esther Rome and Nancy Reame to use blood defied standard laboratory procedure. In the work of eliminating variables to hone in on the intransigent, the process extricated context, in this case, women's menstruating bodies and their interactions with tampon technologies. Saline test fluid and the syngyna apparatus were not only inadequate for their stated purposes of representing women's bodies and fluids, but benefited industrial and corporate needs. In addition, many scientists' beliefs that the syngyna methodology provided accurate data are problematic and can cause harm, because women cannot be reduced to instrumental and predictable machines. This case study highlights the importance of including multiple variables and the materiality of women's bodies in the standard setting process.

\section{Sharra Vostral PhD}

Associate professor, Department of History, Purdue University, West Lafayette, Ind. 


\section{References}

1. Vostral SL. Rely and toxic shock syndrome: a tech nological health crisis. Yale J Biol Med 2011;84 447-59.

2. Follow-up on toxic-shock syndrome - United States. MMWR Morb Mortal Wkly Rep 1980;29:297-9.

3. Toxic-shock syndrome - United States, 19701980. MMWR Morb Mortal Wkly Rep 1981;30: 25-8.

4. National Notifiable Disease Surveillance System. Toxic shock syndrome (other than streptococcol) (TSS) 2011 case definition. Atlanta: Centers for Disease Control and Prevention. Available: wwwn.cdc. gov/nndss/conditions/toxic-shock-syndrome-other -than-streptococcal/case-definition/2011/ (accessed 2017 Jan. 5).

5. Osterholm MT, Davis JP, Gibson RW, et al. Tri-state toxic-shock syndrome study. I. Epidemiologist findings. J Infect Dis 1982;145:431-40.

6. Tampons - Syngina Test by SGS [YouTube video]. Available: https://youtu.be/KYXUQDzSg4o (accessed 2015 Nov. 12).

7. Reame N. Interview with the author (April 6, 2016) [Academic oral history].

8. Nancy Reame to David Swankin, with attached report (May 23, 1983), Boston Women's Health Book Collective, folder 34, box 1. Cambridge (MA): Radcliffe Institute for Advanced Study Harvard University-Schlesinger Library.
9. Rome ER, Wolhandler J, Reame N. The absorbency of tampons. JAMA 1988;259:685-6.

10. US Food and Drug Administration. Labeling for Menstrual Tampons [21 CFR Part 801, Section 801.430]. Federal Register 1989;54:43771.

This article has been peer reviewed.

Sharra Vostral is the author of Under Wraps: A History of Menstrual Hygiene Technology (2008) and TSS: A History (accepted for publication).

This research was awarded a grant by the National Science Foundation. 